\title{
Mesenchymal stem cell-based cell-free strategies: safe and effective treatments for liver injury
}

\author{
Chenxia Hu ${ }^{1,2+}$, Lingfei Zhao ${ }^{3,4,5+}$, Lingjian Zhang ${ }^{1,2 \dagger}$, Qiongling Bao ${ }^{1,2+}$ and Lanjuan $\mathrm{Li}^{1,2^{*}}$
}

\begin{abstract}
Various hepatoxic factors, such as viruses, drugs, lipid deposition, and autoimmune responses, induce acute or chronic liver injury, and 3.5\% of all worldwide deaths result from liver cirrhosis, liver failure, or hepatocellular carcinoma. Liver transplantation is currently limited by few liver donors, expensive surgical costs, and severe immune rejection. Cell therapy, including hepatocyte transplantation and stem cell transplantation, has recently become an attractive option to reduce the overall need for liver transplantation and reduce the wait time for patients. Recent studies showed that mesenchymal stem cell (MSC) administration was a promising therapeutic approach for promoting liver regeneration and repairing liver injury by the migration of cells into liver sites, hepatogenic differentiation, immunoregulation, and paracrine mechanisms. MSCs secrete a large number of molecules into the extracellular space, and soluble proteins, free nucleic acids, lipids, and extracellular vesicles (EVs) effectively repair tissue injury in response to fluctuations in physiological states or pathological conditions. Cell-free-based therapies avoid the potential tumorigenicity, rejection of cells, emboli formation, undesired differentiation, and infection transmission of MSC transplantation. In this review, we focus on the potential mechanisms of MSC-based cell-free strategies for attenuating liver injury in various liver diseases. Secretome-mediated paracrine effects participate in the regulation of the hepatic immune microenvironment and promotion of hepatic epithelial repair. We look forward to completely reversing liver injury through an MSC-based cell-free strategy in regenerative medicine in the near future.
\end{abstract}

Keywords: Mesenchymal stem cell, Cell-free, Treatment, Liver injury, Cell death

\section{Introduction}

Various hepatoxic factors, such as viruses, drugs, lipid deposition, and autoimmune responses, induce acute or chronic liver injury, $[1,2]$ and $3.5 \%$ of all worldwide deaths result from liver cirrhosis, liver failure, or

\footnotetext{
* Correspondence: ljil@zju.edu.cn

${ }^{\dagger}$ Chenxia Hu, Lingfei Zhao, Lingjian Zhang and Qiongling Bao contributed equally to this work.

${ }^{1}$ Collaborative Innovation Center for the Diagnosis and Treatment of

Infectious Diseases, State Key Laboratory for the Diagnosis and Treatment of Infectious Diseases, |The First Affiliated Hospital, School of Medicine, Zhejiang University, Hangzhou, People's Republic of China

${ }^{2}$ National Clinical Research Center for Infectious Diseases, The First Affiliated Hospital, School of Medicine, Zhejiang University, Hangzhou, Zhejiang, People's Republic of China

Full list of author information is available at the end of the article
}

hepatocellular carcinoma [3]. Orthotopic liver transplantation is performed in end-stage liver disease when the remanent liver tissue is unable to regenerate in sufficient time. However, liver transplantation is currently limited by few liver donors, expensive surgical costs, and severe immune rejection. Cell therapy, including hepatocyte transplantation and stem cell transplantation, has recently become an attractive option to reduce the overall need for liver transplantation and reduce the wait time for patients. However, the clinical application of hepatocyte transplantation is limited by the finite proliferative capacity and missing liver functions of human primary hepatocytes, even though this strategy is simpler, less invasive, and safer than surgery [4]. Stem cells 
are multipotent cells that are able to proliferate, selfrenew, and differentiate into various somatic cells in vitro, and they have attracted much attention for restoring tissue function in vivo with little immune rejection. Stem cells can be classified into three categories: embryonic stem cells (ESCs), induced pluripotent stem cells (iPSCs), and mesenchymal stem cells (MSCs) [5]. ESCs are stem cells derived from early-stage embryos and have high potential to undergo multilineage differentiation. Takahashi and Yamanaka transformed mouse fibroblasts into iPSCs by retroviral transduction of four transcription factors (TFs), Oct4, Sox2, Klf4c, and c-Myc [6]. The multipotency and self-renewal ability of these reprogrammed cells are similar to those of ESCs [7]. MSCs can be isolated from various tissues, such as adipose tissue, bone marrow, the placenta, the amnion, menstrual blood, and other tissues [8-12]. The International Society for Cellular Therapy suggested that MSCs could undergo differentiation into adipocytes, osteocytes, and chondrocytes in vitro [13]. Moreover, these cells have more potency and organ availability compared to those of tissue-specific stem cells, no ethical issues compared to those of ESCs, and less tumorigenicity than iPSCs. Considering the advantages of MSCs, they are widely used to repair tissue injury and in regenerative medicine.

Recent studies indicated that MSC administration was a promising therapeutic approach for promoting liver regeneration and repairing liver injury by cell migration into liver sites, hepatogenic differentiation, immunoregulation, and paracrine mechanisms. Despite their beneficial effects in repairing liver injury, the application of MSCs is limited by aberrant differentiation into undesirable cell types and low engraftment in vivo [14, 15]. Moreover, potential tumorigenicity also inhibits the clinical application of MSCs in current regenerative medicine [16]. MSCs demonstrate potential oncogenic transformation after long-term culture in vitro, and they also have the capacity to support tumor growth in vivo $[17,18]$. Hundreds of millions of MSCs are required for transplantation, and the expansion time is approximately 10 weeks before transplantation [19]. MSC transplantation is a risky clinical application since living cells may induce occlusion in the microvasculature [20]. Moreover, transplanted MSCs have a short lifespan and accumulate in lung tissue, which significantly reduces the efficacy of MSC-based regeneration in vivo [21]. However, few MSCs can survive for over 1 week after intravenous administration, which suggests that MSCs participate in repairing tissue injury via paracrine mechanisms [22].

Cell-free-based therapies contribute to liver injury repair via paracrine mechanisms and are safer, cheaper, and more effective treatment options than MSC transplantation. MSCs secrete a large number of molecules into the culture medium, and soluble proteins, free nucleic acids, lipids, and EVs effectively repair tissue injury in response to fluctuations in physiological states or pathological conditions [23]. Soluble and applicable factors can be separated from the MSC-derived secretome and microvesicle fraction via centrifugation, filtration, polymer precipitation-based methodologies, ion exchange chromatography, and size-exclusion chromatography [24]. The manipulation of the MSC-derived secretome is similar to that of pharmaceutical agents, and the storage of the MSC-derived secretome for a long period of time can be performed without toxic cryopreservative agents $[21,25]$. Furthermore, the in vitro cellfree MSC-sourced secretome is economical and practical for clinical applications [26]. Cell-free-based therapies avoid the potential tumorigenicity, rejection of cells, emboli formation, undesired differentiation, and infection transmission of MSC transplantation. Although multiple studies have shown significant effects of MSC-derived secretomes in treating liver diseases, the exact key molecules in the MSC secretome need to be further investigated. In this review, we focus on the potential mechanisms by which MSC-based cell-free strategies attenuate liver injury in various liver diseases. Secretomemediated paracrine effects participate in the regulation of the hepatic immune microenvironment and the promotion of hepatic epithelial repair.

\section{Current forms of liver injury}

The liver consists of multiple functional or interstitial cells, including hepatocytes, cholangiocytes, Kupffer cells, sinusoidal endothelial cells, hepatic stellate cells (HSCs), and dendritic cells, and this organ performs synthesis and secretion functions associated with digestion [27]. However, external injury always initiates a pool of various hepatoxic factors or cytokines in injured sites, which exacerbates internal injury in liver tissue. It is worth noting that the liver may initiate the recovery process and liver regeneration can occur after timely restoration of blood flow or oxygen in vivo via replenishment of cellular adenosine triphosphate (ATP) and controlling excessive reactive oxygen species (ROS); however, ischemia-reperfusion (I/R) injury and the subsequent reintroduction of oxygen-rich blood into liver tissue will promote liver cell apoptosis and exacerbate the progression of liver dysfunction [28]. If long-term ischemia occurs, cell death and cell damage are initiated after the activation of apoptotic or necrotic pathways, and the late stage of liver injury results in the generation of fibrotic tissue and reduced liver function [28]. In addition to hepatic I/R, other chronic liver injury factors, such as viral infection, drugs, high-fat diet consumption, genetic mutations, and biliary tract diseases [29], also 
largely impair the functions of epithelial cells and activate fibrogenesis and inflammation by activating extracellular matrix (ECM)-producing cells in the liver tissue. These changes further lead to collagen deposition and the generation of irreversible intrahepatic scar tissue in the liver [30]. At the end stage of liver cirrhosis, patients have multiple complications, such as portal hypertension, acute-on-chronic liver failure, or hepatocarcinoma. It is generally accepted that acute liver failure (ALF) occurs in patients without a history of liver disease who develop an international normalized ratio (INR) $>1.5$ and any grade of hepatic encephalopathy (HE) within 26 weeks of the onset of illness [31]. On the other hand, acute-on-chronic liver failure (ACLF) is defined as a patient with chronic liver disease who develops liver failure [32]. The balance of hepatocyte cell death and regeneration is disrupted in patients with liver failure, and a majority of hepatocytes undergo apoptosis and necrosis, which are mediated by a multitude of interrelated factors and signals, including caspases, oxidative stress and antioxidants, transcription factors, cytokines, chemokines, and kinases [33].

\section{Cell death and liver injury}

In contrast to most other organs, liver regeneration is also initiated to repair liver injury and compensate for liver function, which is observed in 2/3 partial hepatectomy animal models [34]. On the other hand, hepatocyte injury also results in ATP depletion, which is followed by mitochondrial depolarization, lysosomal breakdown, cell swelling, bleb formation, and cell membrane rupture [35].

Several forms of cell death, including apoptosis, necroptosis, necrosis, and autophagy, are noted in injured liver tissue [36]. However, apoptosis and necrosis are two major forms of cell death in liver diseases. Autophagy is a protective process that delivers cytoplasmic material for degradation in liver tissue to maintain hepatic homeostasis, and hepatic autophagy also includes specific and selective types, including mitophagy and lipophagy [37, 38]. Apoptosis is a kind of programmed cell death that participates in removing damaged cells to protect against external disturbances and maintain liver homeostasis. Hepatocyte necrosis is usually observed in different liver diseases, such as $\mathrm{I} / \mathrm{R}$ injury or druginduced liver injury [39]. Cellular morphology undergoes changes, including chromatin condensation, DNA fragmentation, cell shrinkage, and membrane budding, in an ATP-dependent manner after the initiation of hepatocyte apoptosis [40]. Characteristic chromatin condensation and fragmentation result in the packaging of organelles and pyknosis in the cytoplasm, which progresses to apoptosis [41]. In chronic liver disease, the apoptosis rate is higher than the necrosis rate, although both forms of cell death are basic pathogenic mechanisms of liver injury [42]. Mild liver injury factors first promote the translocation of phosphatidylserine from the cytoplasm into the extracellular membrane, subsequently triggering the activation of caspase proteins, the release of mitochondrial factors such as cytochrome $\mathrm{c}$ and apoptosis-inducing factor, and DNA fragmentation [40]. Necrosis is characterized by membrane blebbing, cytoplasmic swelling, mitochondrial swelling, mitochondrial calcification, disintegration of organelles, and cell lysis [43]. However, severe liver injury factors promote imbalanced ion homeostasis, DNA digestion, postlytic DNA fragmentation, and cellular necrosis in an energyindependent manner [44]. Necrosis is another kind of cell death that is characterized by uncontrolled damage accompanied by cell membrane damage, cell swelling, and cellular inflammation [45]. Necrosis robustly recruits inflammatory cells into the liver parenchyma and exacerbates the release of inflammatory factors to facilitate liver disease [46].

In conclusion, various liver injury factors such as viruses, drugs, lipid deposition, and autoimmune responses result in different forms of cell death, such as apoptosis or necrosis, depending on the severity of the insult. Different liver injury factors ultimately lead to liver failure when a large number of liver parenchymal cells die and the cell death rate outpaces the liver regenerative capabilities. Moreover, cell death in liver tissue activates the liver inflammatory response and subsequent multiorgan ramifications and carries a grave prognosis.

\section{The secretion and composition of MSC-derived soluble factors}

In vitro cultured MSCs secreted a certain number of soluble factors into Dulbecco's modified Eagle's medium (DMEM) to generate MSC-derived conditioned medium (MSC-CM). There are many soluble bioactive factors, including cytokines, chemokines, immunomodulatory molecules, and growth factors, in MSC-CM that exert immunomodulatory functions, inhibit cell death and fibrosis, stimulate vascularization, promote tissue remodeling, and recruit other cells in various tissues. MSC-CM is able to transdifferentiate tissue-specific progenitor cells into somatic cells and participate in tissue injury repair via its paracrine effects [47]. MSC-secreted EVs can encapsulate various paracrine factors, and they can be classified into three categories, exosomes $(30-100 \mathrm{~nm})$, microvesicles $(100-1000 \mathrm{~nm})$, and apoptotic bodies $(500-2000 \mathrm{~nm})$, according to their origin and size [23]. Exosomes are nanosized EVs that originate from the inward budding of the membrane of multivesicular bodies (MVBs) and have remarkable physiological properties. Exosomes are released after the fusion of MVBs with the plasma membrane, and these biological factors are further taken up into target cells [48]. Exosomes can be sedimented by centrifugation at $100,000 g$, and their 
concentration varies from 1.13 to $1.19 \mathrm{~g} \mathrm{ml} / \mathrm{L}$ in sucrose solutions [49]. The nanometer-sized features made exosomes easy to transfer through blood and other biological fluids. The proteins and miRNAs contained in exosomes are functionally complex and participate in immune regulation, bioenergetics, energy metabolism, antioxidative stress, and tissue regeneration in transplant recipients [50]. Lai et al. demonstrated that the catalytic capacity of exosome-derived enzymes changed according to the surrounding microenvironment. That group concluded that this specificity made exosomes safer than other therapeutic agents [51]. Exosomes protect against the degradation of active ingredients by encapsulating factors within their membranes and facilitating intracellular uptake via endocytosis [52]. In addition, MSCderived soluble factors deliver multiple factors, such as DNA, mRNA, microRNA, proteins, lipids, and organelles, to recipient tissues and target cells via early endocytosis and subsequent fusion [53, 54]. In particular, a gene ontology analysis showed that various miRNAs, such as miR148a, miR532-5p, miR378, and let-7f, are enriched in the culture medium of MSCs, and these miRNAs can be isolated to regulate different pathways, including cellular transport, angiogenesis, proteolysis, and apoptosis [55-59]. Unique proteins were suggested to exist only in MSC-derived exosomes compared to their parental MSCs [60]. It is worth noting that culture conditions such as hypoxia, ischemia, and inflammation effectively influence the composition of MSC-derived soluble factors [61-63]. On the other hand, soluble factors isolated from MSCs from different sources also have different transcriptome and proteome profiles [64]. MSC-derived soluble factors are preferentially taken up by injured tissues and further mediate cell communication in both adjacent and remote areas via paracrine and endocrine signaling.

\section{Quality control of EVs}

In good manufacturing practice (GMP), there are three important issues for exosome generation: cell culture, purification, and quality control. The main challenge in the GMP of exosomes is quality control since the sources of MSC-producing exosomes are diverse [65]. For further clinical applications and academic studies, appropriate quality control is important when manufacturing clinical-grade EVs with a GMP-compliant process and developing cell-free therapeutics. Determining the quantity, identity, purity, and potency assays of EVs are known as routine quality control criteria.

Total amounts of proteins, lipids, or RNAs can be determined when quantifying EVs; however, nanoparticle tracking analysis (NTA), resistive pulse sensing (RPS), and dynamic light scattering (DLS) are used to determine the number and size of EVs. The most widely used
NTA determines the number and size of particles by tracking the Brownian motion of single particles in an aqueous solution [66]. Quantification of EVs remains extremely challenging, and new methods, such as nanoflow cytometry, direct stochastic optical reconstruction microscopy, ExoCounter with optical disc technology, and imaging flow cytometry, have been developed to effectively quantify EVs [67-70]. The purification process can be described as three steps: filtration to remove the cellular debris, concentration of the CM, and exosome isolation from the concentrated CM [71]. To achieve higher specificity, investigators should remove impurities step-by-step. Several proteins, including CD9, CD63, CD81, tumor susceptibility gene (TSG)101, and Alix, which are highly enriched in exosomes, are recommended as specific markers for determining the identity of EVs [72-75]. To determine the purity for quality control, the particle-to-protein, protein-to-lipid, or RNA-toparticle ratios are common markers for monitoring the purity of EVs [72]. There are also some impurities, such as antibiotics and serum, that should be excluded from the cell culture medium when monitoring the removal of potential hazardous factors [76]. On the other hand, another criterion is the absence of several proteins, including histones, lamin $\mathrm{A} / \mathrm{C}$, glucose-regulated protein 94, Golgi matrix protein 130, and cytochrome C, since strict cellular localization prohibits the enrichment of these intracellular proteins [72]. Although various biological and biochemical assays are used to determine the potency of EVs or exosomes, it is still difficult to establish a single, standard potency assay since the cargos of EVs in vivo are so complex $[77,78]$.

\section{MSC-derived soluble factors are effective for treating liver diseases}

Transplantation of MSC-CM and exosomes is the main therapy for treating acute or chronic liver injury (Table 1). Transplantation significantly improved liver function by inhibiting apoptosis, necrosis, oxidative stress, inflammation, infiltration of immune cells, immune rejection, HSC activation, etc. (Fig. 1).

\section{MSC-CM for treating liver diseases}

Infusion of MSC-CM immediately before liver irradiation obviously inhibited the apoptosis of sinusoidal endothelial cells (SECs) and the histopathological changes in the irradiated liver by attenuating liver inflammation [79]. MSC-CM attenuated liver injury and provided a survival benefit in rats with $5 \%$ reduced-size liver transplantation (RSLT) by reducing the apoptosis rate of hepatocytes and SECs and reducing the secretion of proinflammatory cytokines, infiltration of neutrophils, and activation of Kupffer cells. Furthermore, the expression of vascular endothelial growth factor (VEGF) and 


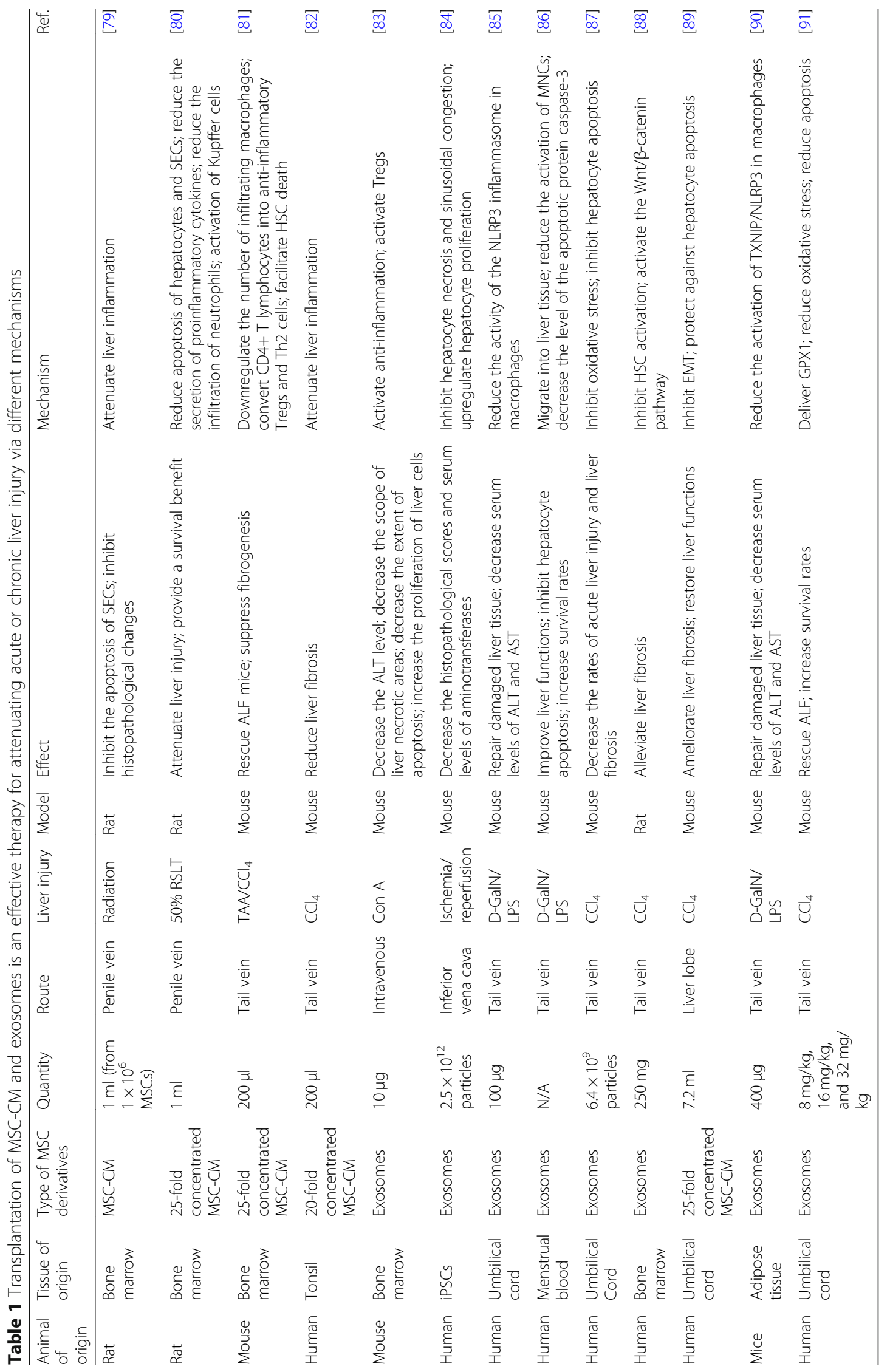




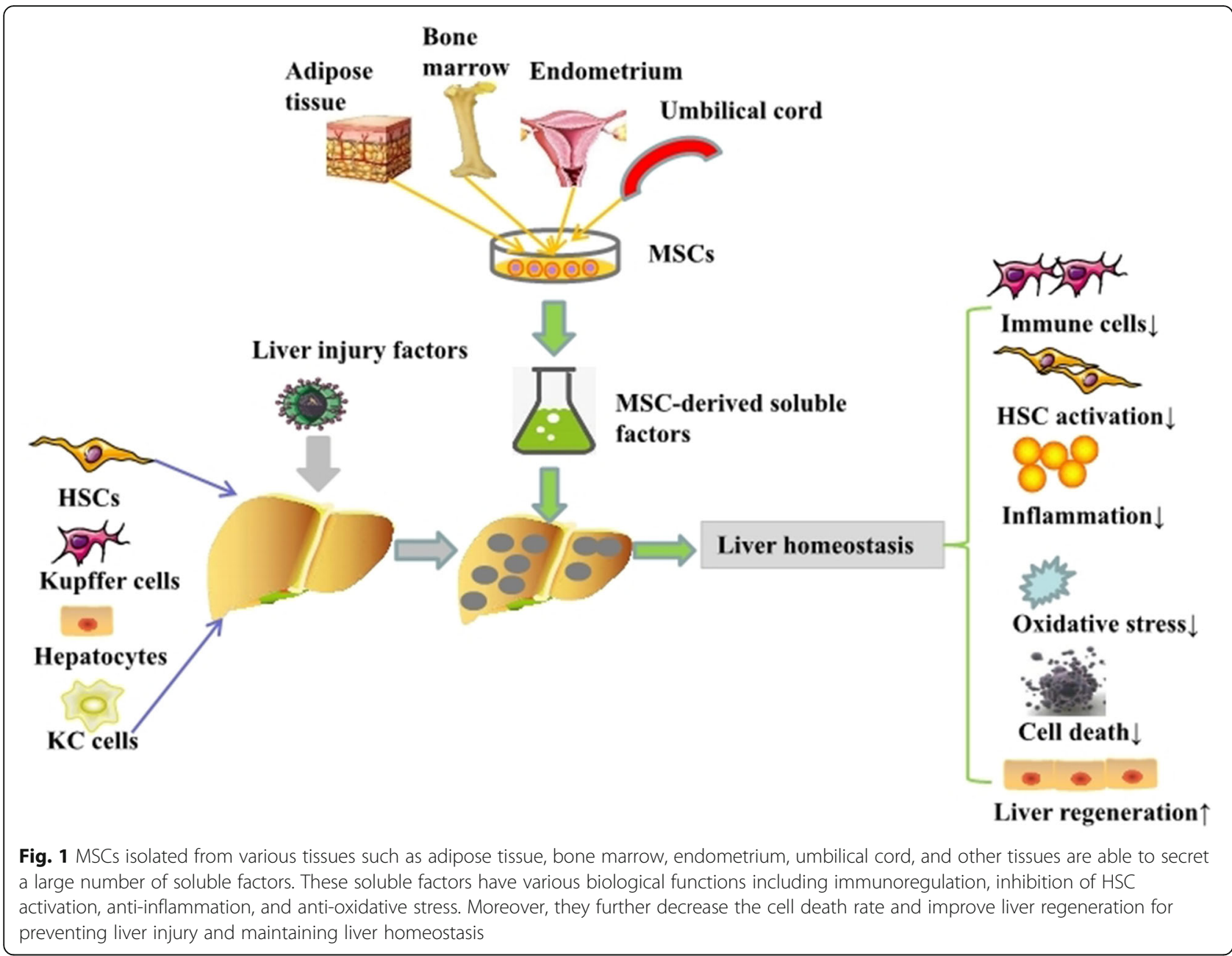

matrix metallopeptidase 9 was also improved to promote liver regeneration in the liver grafts of recipient rats [80]. MSC-derived CM partially ameliorates ALF while significantly suppressing fibrogenesis, necroinflammation, liver apoptosis, and activation of HSCs and improving glycogen synthesis and storage and liver regeneration. Furthermore, MSC-CM reduced infiltrating macrophages, converted $\mathrm{CD}_{4}^{+} \mathrm{T}$ lymphocytes into anti-inflammatory Tregs and Th2 cells, and facilitated HSC death in liver tissue [81]. Both MSC-CM and interleukin (IL)-1Ra isolated from MSC-CM significantly reduced liver fibrosis by attenuating liver inflammation and inducing alpha-1 type I collagen, transforming growth factor (TGF)- $\beta 1$, and tissue inhibitor of metalloproteases 1 [82].

\section{MSC-derived exosomes for treating liver diseases}

MSC-derived soluble factors isolated from MSC-CM can also protect against liver inflammation and liver injury. Tamura et al. demonstrated that exosomes escape being trapped in lung tissue and are largely distributed in injured liver tissue. MSC-derived exosomes comparably improved liver functions and hepatocyte proliferation but decreased the apoptosis rate and scope of liver necrotic areas by exerting anti-inflammatory effects and activating Tregs in comparison to those of the MSC group [83]. These exosomes were proven to exert protective effects on liver injury models in a dose-dependent manner. $\mathrm{Du}$ et al. demonstrated that MSC-derived exosomes significantly upregulated hepatocyte proliferation in a dosedependent manner and could directly fuse with target hepatocytes. Consequently, MSC-derived exosomes decreased the histopathological scores and serum levels of aminotransferases by inhibiting hepatocyte necrosis and sinusoidal congestion and upregulating hepatocyte proliferation in the ischemia/reperfusion injury model [84]. Exosomes from human umbilical cord-derived MSCs significantly decreased the serum levels of alanine aminotransferase (ALT) and aspartate aminotransferase (AST) and repaired injured liver tissue in an ALF mouse model after reducing TXNIP/NLRP3 inflammasome activation and its downstream inflammatory factors, including caspase-1, IL-1 $\beta$, and IL-6 [85]. MSC-derived 
exosomes dose-dependently inhibited apoptosis in Dgalactoside (D-GalN)/lipopolysaccharide (LPS)-treated AML12 cells in vitro. In addition, transplantation of exosomes significantly inhibited hepatocyte apoptosis and increased the survival rates of D-GalN/LPS-induced ALF mice by migrating to liver tissue, inhibiting liver mononuclear cells and downregulating the apoptotic protein caspase-3 [86]. Jiang et al. showed that MSC-derived exosomes alleviated carbon tetrachloride $\left(\mathrm{CCl}_{4}\right)$-induced acute liver injury and liver fibrosis via the inhibition of oxidative stress and hepatocyte apoptosis and further improved the antioxidant and hepatoprotective effects of bifendate treatment [87]. In addition, exosomes more significantly alleviated $\mathrm{CCl}_{4}$-induced liver fibrosis than MSCs, as demonstrated by a reduction in collagen accumulation and enhanced liver functions through a reduction in liver inflammation, upregulation of hepatocyte regeneration, and inhibition of HSC activation through the $\mathrm{Wnt} / \beta$-catenin pathway [88]. Exosomes from human umbilical cord MSCs significantly protected against liver dysfunction, as shown by decreased ALT levels and TGF- $\beta 1$ and phosphorylated Smad2 expression. Exosomes also decreased collagen deposition and ameliorated $\mathrm{CCl}_{4}$-induced liver fibrosis by inhibiting epithelialto-mesenchymal transition (EMT), attenuating hepatic inflammation, and eliminating hepatocyte apoptosis [89].

\section{Exosomes from gene-modified MSCs for treating liver diseases}

Intriguingly, gene modification of MSCs provides additional therapeutic effects of exosomes in liver diseases. Liu et al. showed that exosomes from adipose-derived MSCs also improved liver functions through a similar pathway. However, knockout of miR-17 in MSCs abolished the therapeutic effects of exosomes from miR-17knockout MSCs in ALF mice, which indicated that miR17 plays a critical role in the anti-inflammatory function of exosomes [90]. A dose-dependent effect was also observed after gavage administration of MSC-derived exosomes. Although $8 \mathrm{mg} / \mathrm{kg}$ MSC-derived exosomes failed to rescue ALF animals, 16 and $32 \mathrm{mg} / \mathrm{kg}$ MSC-derived exosomes improved the survival rate to 60 and $90 \%$, respectively. In addition, Yan et al. demonstrated that exosomes effectively rescued ALF mice by reducing oxidative stress and apoptosis in liver tissue, and knockdown of glutathione peroxidase 1 (GPX1) in MSCs abrogated the protective effects of exosomes and inhibited the recovery of hepatic oxidative injury in ALF mice [91].

\section{How can the therapeutic effects of MSC-based cell-free strategies be improved?}

To further improve the therapeutic effects, modification of the MSC microenvironments and gene modification of MSCs can consequently alter the composition of proteins and vesicular contents of MSC-derived soluble factors (Table 2).

\section{Pretreatment or cotreatment for MSC-based cell-free therapy}

The common oxygen level is approximately $21 \% \mathrm{O}_{2}$ for standard cell culture, and this oxygen concentration is not the same as that in the in vivo microenvironment. The physiological oxygen concentration in tissues varies from $1 \%$ in cartilage and bone marrow to $12 \%$ in peripheral blood [92]. To improve MSC multipotency, proliferation, and secretion of cytoprotective molecules, hypoxic conditions have been proven to significantly improve the survival rate of MSCs in the harsh environments of injury sites after transplantation [93, 94]. CM derived from hypoxic $\left(10 \% \mathrm{O}_{2}\right)$ MSCs more significantly improved the biochemical parameters and histological results in acetaminophen-induced ALF models by reducing liver inflammation and improving liver regeneration than MSC-CM isolated from a normal oxygen culture environment [95]. CM from MSCs cultured at lower (5\%) $\mathrm{O}_{2}$ levels more significantly inhibited the activation of inflammation and attenuated hepatocyte necrosis in liver tissue than CM from normoxic MSCs, and hypoxic MSC-derived CM more robustly downregulated oxygen tension and accelerated the healing process in damaged liver tissue of ALF models than CM from normoxic MSCs. Furthermore, CM derived from MSCs cultured in $1 \%$ hypoxia showed higher levels of IL-6, tumor necrosis factor (TNF)- $\alpha$, hepatocyte growth factor (HGF), and VEGF, and these extremely hypoxic CMs significantly increased the number of proliferating cells in liver tissue via the activation of JAK/STAT3 signaling [96]. Proteins isolated from mildly hypoxic MSCs (5\% and 10\% $\mathrm{O}_{2}$ ) showed better effects in treating acetaminophen-induced ALF than those from normal MSCs by inhibiting inflammatory reactions and reducing hepatocyte necrosis in damaged liver. This group further showed that even moderate hypoxia produced discrete changes in the expression of various subsets of proteins responsible for intracellular respiration and cell signaling [97].

To further improve the therapeutic effects of MSC$\mathrm{CM}$, MSCs were cocultured with hepatocytes in vitro to improve MSC secretion of protective factors. In comparison to MSC-CM and CM from hepatocytes, the cocultured MSC-CM significantly prolonged the survival time of ALF rats by preventing liver injury and promoting liver tissue repair [98]. Cotreatment with melatonin and MSC-derived exosomes markedly decreased the liver injury score and AST level in the liver I/R group. Intriguingly, the cotreatment group showed comparably low levels of inflammatory factors, apoptosis-related proteins, oxidative stress, DNA damage, and mitochondrial damage to those of the normal group [99]. 
Table 2 Improvement in the efficacy of MSC-derived soluble factors in treating liver diseases via different mechanisms

\begin{tabular}{|c|c|c|c|c|c|c|c|c|c|c|}
\hline $\begin{array}{l}\text { Animal } \\
\text { of } \\
\text { origin }\end{array}$ & $\begin{array}{l}\text { Tissue of } \\
\text { origin }\end{array}$ & Pretreatment & $\begin{array}{l}\text { Type of MSC } \\
\text { derivatives }\end{array}$ & Quantity & Route & Liver injury & Model & Effect & Mechanism & Ref. \\
\hline Mouse & $\begin{array}{l}\text { Bone } \\
\text { marrow }\end{array}$ & Hypoxia & MSC-CM & $5 \mathrm{mg}$ & Intraperitoneal & Acetaminophen & Mouse & $\begin{array}{l}\text { Improve } \\
\text { biochemical } \\
\text { parameters and } \\
\text { histological scores }\end{array}$ & $\begin{array}{l}\text { Reduce } \\
\text { inflammation; } \\
\text { improve liver } \\
\text { regeneration }\end{array}$ & [95] \\
\hline Human & Adipose & Hypoxia & $\begin{array}{l}\text { 25-fold } \\
\text { concentrated } \\
\text { MSC-CM }\end{array}$ & $0.1 \mathrm{ml}$ & Tail vein & $\begin{array}{l}\text { Partial } \\
\text { hepatectomy }\end{array}$ & Mouse & $\begin{array}{l}\text { Increase the } \\
\text { number of } \\
\text { proliferative liver } \\
\text { cells }\end{array}$ & $\begin{array}{l}\text { Activate JAK } \\
\text { STAT3 signaling }\end{array}$ & [96] \\
\hline Mouse & $\begin{array}{l}\text { Bone } \\
\text { marrow }\end{array}$ & Hypoxia & $\begin{array}{l}\text { Protein } \\
\text { composition }\end{array}$ & 10 mg/ml & Intraperitoneal & Acetaminophen & Mouse & $\begin{array}{l}\text { Reduce oxygen } \\
\text { levels; accelerate } \\
\text { healing in } \\
\text { damaged liver } \\
\text { tissue }\end{array}$ & $\begin{array}{l}\text { Inhibit the } \\
\text { activation of } \\
\text { inflammation; } \\
\text { attenuate } \\
\text { hepatocyte } \\
\text { necrosis }\end{array}$ & [97] \\
\hline Rat & $\begin{array}{l}\text { Bone } \\
\text { marrow }\end{array}$ & $\begin{array}{l}\text { Coculture with } \\
\text { hepatocytes }\end{array}$ & $\begin{array}{l}\text { 25-fold } \\
\text { concentrated } \\
\text { MSC-CM }\end{array}$ & $7.2 \mathrm{ml}$ & Tail vein & D-GalN & Rat & $\begin{array}{l}\text { Prolong the } \\
\text { survival time of } \\
\text { ALF rats }\end{array}$ & $\begin{array}{l}\text { Prevent liver } \\
\text { injury; promote } \\
\text { liver tissue } \\
\text { repair }\end{array}$ & [98] \\
\hline Mouse & $\begin{array}{l}\text { Bone } \\
\text { marrow }\end{array}$ & $\begin{array}{l}\text { miR-223 } \\
\text { overexpression }\end{array}$ & Exosomes & N/A & Intraperitoneal & $\begin{array}{l}\text { Liver antigens } \\
\text { S100 }\end{array}$ & Mouse & $\begin{array}{l}\text { Reverse } \\
\text { autoimmune } \\
\text { hepatitis }\end{array}$ & $\begin{array}{l}\text { Downregulate } \\
\text { the release of } \\
\text { cytokines such } \\
\text { as NLRP3 and } \\
\text { caspase-1 }\end{array}$ & [101] \\
\hline Mouse & $\begin{array}{l}\text { Adipose } \\
\text { tissue }\end{array}$ & $\begin{array}{l}\text { miR181-5p } \\
\text { overexpression }\end{array}$ & Exosomes & $40 \mu \mathrm{g}$ & Intrasplenic & $\mathrm{CCl}_{4}$ & Mouse & $\begin{array}{l}\text { Inhibit the } \\
\text { deposition of } \\
\text { collagen I, } \\
\text { vimentin, a-SMA } \\
\text { and fibronectin in } \\
\text { the liver }\end{array}$ & $\begin{array}{l}\text { Activate } \\
\text { autophagy; } \\
\text { downregulate } \\
\text { Stat3 and Bcl-2 } \\
\text { in HSCs }\end{array}$ & [102] \\
\hline
\end{tabular}

Culture conditions may influence the regenerative and immunomodulatory capacities of MSC-derived soluble factors, and the optimization of culture conditions will contribute to the further regeneration of liver tissues. According to current studies, pretreatment or cotreatment of MSCs with different factors exerts decisive effects on the therapeutic effects of MSC-based cell-free treatment in recipients. However, the study number is limited, and we suggest exploring the detailed treatments of MSCs and their related mechanisms in depth.

\section{Soluble factors from MSCs with gene modifications}

Valadi et al. first reported that exosomes effectively transferred functional mRNAs or miRNAs into target cells since they found that there were multiple new mouse-derived proteins in human mast cells after the transplantation of mouse MSC-derived exosomes [100]. Current studies have tried to alter the delivered factors to improve the therapeutic effects of MSC-derived soluble factors.

MSCs were infected with pre-miR-223 and transfected with a miR-223 inhibitor to generate exosomes containing miR-223 and exosomes without miR-223, respectively. Exosomes and exosomes ${ }^{\text {miR-223(+) }}$ significantly reversed autoimmune hepatitis by downregulating cytokines such as NLRP3 and caspase-1, while exosomes ${ }^{\text {miR-223(-) }}$ did not exert protective effects in the experimental model of autoimmune hepatitis. This finding indicated that miR-223 was a key factor participating in the immunoregulation of MSC-derived exosomes to protect against liver injury [101]. In addition, exosomes ${ }^{\text {miR181-5p }(+)}$ delivered miR181$5 p$ to injured liver tissue and inhibited the deposition of collagen I, vimentin, $\alpha$-SMA, and fibronectin in fibrotic livers after activating autophagy and downregulating STAT3 and Bcl-2 in HSCs [102].

\section{Conclusions}

MSC-based cell-free products protect against the potential risks associated with the use of native or engineered MSCs in vivo; moreover, an increasing number of studies have shown that the therapeutic effects of MSCbased cell-free products are equal to those of MSCs. In comparison to MSCs, MSC-derived soluble factors are easier to generate in advance, more stable for storage and transport, and more convenient to control in terms of quality and quantity. As transplantation of MSCderived soluble factors avoids delivering active cells, infusion of these factors is less immunogenic, less tumorigenic, and less likely to result in exogenic infections, including cytomegalovirus and herpes simplex virus 
infections [103]. All these advantages make MSCderived soluble factors promising alternatives to MSC therapy in treating liver diseases. However, current studies have not clarified the detailed factors in MSC-derived soluble factors in vitro and in vivo. The presence of different bioactive molecules mediates the different biological activities of MSC-derived exosomes, which may also influence their final effects in vivo. Furthermore, questions about the characterization, potency, and quantification of MSC-derived exosomes must be addressed before their clinical application is feasible. As MSCderived soluble factors effectively deliver various cargos in vivo, the identification and purification of these factors should be explored to avoid the administration of potentially harmful vesicles or molecules in the human body. In our opinion, pretreatments or gene modifications may also serve as effective strategies to improve the therapeutic effects of MSC-based cell-free products.

\begin{abstract}
Abbreviations
ESCs: Embryonic stem cells; iPSCs: Induced pluripotent stem cells; MSCs: Mesenchymal stem cells; TFs: Transcription factors; HSCs: Hepatic stellate cells; ATP: Adenosine triphosphate; ROS: Reactive oxygen species; I/ R: Ischemia-reperfusion; ECM: Extracellular matrix; ALF: Acute liver failure; INR: International normalized ratio; HE: Hepatic encephalopathy; ACLF: Acuteon-chronic liver failure; DMEM: Dulbecco's modified Eagle's medium; MSCCM: MSC-derived conditioned medium; EVs : Extracellular vesicles; MVBs: Multivesicular bodies; GMP: Good manufacturing practice; NTA: Nanoparticle tracking analysis; RPS: Resistive pulse sensing; DLS: Dynamic light scattering; TSG: Tumor susceptibility gene; SEC: Sinusoidal endothelial cell; RSLT: Reduced-size liver transplantation; VEGF: Vascular endothelial growth factor; IL: Interleukin; TGF: Transforming growth factor; ALT: Alanine aminotransferase; AST: Aspartate aminotransferase; D-GalN: DGalactoside; LPS: Lipopolysaccharide; $\mathrm{CCl}_{4}$ : Carbon tetrachloride; EMT: Epithelial-to-mesenchymal transition; GPX1: Glutathione peroxidase1; TNF: Tumor necrosis factor; HGF: Hepatocyte growth factor
\end{abstract}

\section{Acknowledgements}

Not applicable.

\section{Authors' contributions}

Lanjuan Li contributed to the conception of this study. Chenxia Hu and Lingfei Zhao were responsible for the literature review. Chenxia Hu, Lingfei Zhao, and Qiongling Bao drafted the manuscript. Lingjian Zhang revised the manuscript. All authors read and approved the final manuscript.

\section{Funding}

This work was supported by the National Natural Science Foundation of China (no. 81700553), Zhejiang basic public welfare research program (no. LGF2OH030008), and the Independent Fund of State Key Laboratory for Diagnosis and Treatment of Infectious Diseases, Zhejiang University.

\section{Availability of data and materials}

All data are included in this published article.

\section{Ethics approval and consent to participate}

Not applicable.

\section{Consent for publication}

Not applicable.

\section{Competing interests}

The authors declare that they have no competing interests.

\section{Author details}

${ }^{1}$ Collaborative Innovation Center for the Diagnosis and Treatment of Infectious Diseases, State Key Laboratory for the Diagnosis and Treatment of Infectious Diseases, |The First Affiliated Hospital, School of Medicine, Zhejiang University, Hangzhou, People's Republic of China. ${ }^{2}$ National Clinical Research Center for Infectious Diseases, The First Affiliated Hospital, School of Medicine, Zhejiang University, Hangzhou, Zhejiang, People's Republic of China. ${ }^{3}$ Kidney Disease Center, First Affiliated Hospital, College of Medicine, Zhejiang University, Hangzhou, People's Republic of China. ${ }^{4}$ Key Laboratory of Kidney Disease Prevention and Control Technology, Hangzhou, Zhejiang Province, People's Republic of China. ${ }^{5}$ Institute of Nephrology, Zhejiang University, Hangzhou, Zhejiang, People's Republic of China.

Received: 7 July 2020 Revised: 17 August 2020

Accepted: 21 August 2020 Published online: 03 September 2020

\section{References}

1. Lee CA, Sinha S, Fitzpatrick E, Dhawan A. Hepatocyte transplantation and advancements in alternative cell sources for liver-based regenerative medicine. J Mol Med (Berl). 2018;96(6):469-81.

2. Zhang S, Yang Y, Fan L, Zhang F, Li L. The clinical application of mesenchymal stem cells in liver disease: the current situation and potential future. Ann Transl Med. 2020;8(8):565.

3. Asrani SK, Devarbhavi H, Eaton J, Kamath PS. Burden of liver diseases in the world. J Hepatol. 2019;70(1):151-71.

4. Forbes SJ, Alison MR. Regenerative medicine. Knocking on the door to successful hepatocyte transplantation. Nat Rev Gastroenterol Hepatol. 2014; 11(5):277-8.

5. Miceli M, Baldi D, Cavaliere C, Soricelli A, Salvatore M, Napoli C. Peripheral artery disease: the new frontiers of imaging techniques to evaluate the evolution of regenerative medicine. Expert Rev Cardiovasc Ther. 2019;17(7): 511-32.

6. Takahashi K, Yamanaka S. Induction of pluripotent stem cells from mouse embryonic and adult fibroblast cultures by defined factors. Cell. 2006;126(4): 663-76.

7. Nakagawa M, Koyanagi M, Tanabe K, Takahashi K, Ichisaka T, Aoi T, Okita K, Mochiduki Y, Takizawa N, Yamanaka S. Generation of induced pluripotent stem cells without Myc from mouse and human fibroblasts. Nat Biotechnol. 2008;26(1):101-6.

8. Hu C, Zhao L, Li L. Current understanding of adipose-derived mesenchymal stem cell-based therapies in liver diseases. Stem Cell Res Ther. 2019;10(1): 199.

9. Shi D, Zhang J, Zhou Q, Xin J, Jiang J, Jiang L, Wu T, Li J, Ding W, Sun S, Zhou N, Zhang L, Jin L, Hao S, Chen P, Cao H, Li M, Li L, Chen X. Quantitative evaluation of human bone mesenchymal stem cells rescuing fulminant hepatic failure in pigs. Gut. 2017;66(5):955-64.

10. Hu C, Cao H, Pan X, Li J, He J, Pan Q, Xin J, Yu X, Wang Y, Zhu D, Li L. Adipogenic placenta-derived mesenchymal stem cells are not lineage restricted by withdrawing extrinsic factors: developing a novel visual angle in stem cell biology. Cell Death Dis. 2016;7(3):e2141.

11. Lindenmair A, Hatlapatka T, Kollwig G, Hennerbichler S, Gabriel C, Wolbank $\mathrm{S}$, Redl H, Kasper C. Mesenchymal stem or stromal cells from amnion and umbilical cord tissue and their potential for clinical applications. Cells. 2012; 1(4):1061-88.

12. Chen L, Qu J, Cheng T, Chen X, Xiang C. Menstrual blood-derived stem cells: toward therapeutic mechanisms, novel strategies, and future perspectives in the treatment of diseases. Stem Cell Res Ther. 2019;10(1): 406.

13. Dominici M, Le Blanc K, Mueller I, Slaper-Cortenbach I, Marini F, Krause D, Deans R, Keating A, Prockop D, Horwitz E. Minimal criteria for defining multipotent mesenchymal stromal cells. The International Society for Cellular Therapy position statement. Cytotherapy. 2006;8(4):315-7.

14. Volarevic V, Markovic BS, Gazdic M, Volarevic A, Jovicic N, Arsenijevic N, Armstrong L, Djonov V, Lako M, Stojkovic M. Ethical and safety issues of stem cell-based therapy. Int J Med Sci. 2018;15(1):36-45.

15. Kurtz A. Mesenchymal stem cell delivery routes and fate. Int J Stem Cells. 2008;1(1):1-7.

16. Barkholt $L$, Flory E, Jekerle $V$, Lucas-Samuel $S$, Ahnert $P$, Bisset $L$, Büscher $D$ Fibbe W, Foussat A, Kwa M, Lantz O, Mačiulaitis R, Palomäki T, Schneider CK, Sensebé L, Tachdjian G, Tarte K, Tosca L, Salmikangas P. Risk of tumorigenicity in mesenchymal stromal cell-based therapies--bridging 
scientific observations and regulatory viewpoints. Cytotherapy. 2013;15(7): 753-9.

17. Prockop DJ, Brenner M, Fibbe WE, Horwitz E, Le Blanc K, Phinney DG, Simmons PJ, Sensebe L, Keating A. Defining the risks of mesenchymal stromal cell therapy. Cytotherapy. 2010;12(5):576-8.

18. Miura M, Miura Y, Padilla-Nash HM, Molinolo AA, Fu B, Patel V, Seo BM, Sonoyama W, Zheng JJ, Baker CC, Chen W, Ried T, Shi S. Accumulated chromosomal instability in murine bone marrow mesenchymal stem cells leads to malignant transformation. Stem Cells. 2006;24(4):1095-103.

19. Sotiropoulou PA, Perez SA, Salagianni M, Baxevanis CN, Papamichail M. Characterization of the optimal culture conditions for clinical scale production of human mesenchymal stem cells. Stem Cells. 2006;24(2):462-71.

20. Furlani D, Ugurlucan M, Ong L, Bieback K, Pittermann E, Westien I, Wang W, Yerebakan C, Li W, Gaebel R, Li RK, Vollmar B, Steinhoff G, Ma N. Is the intravascular administration of mesenchymal stem cells safe? Mesenchymal stem cells and intravital microscopy. Microvasc Res. 2009;77(3):370-6.

21. Eggenhofer E, Luk F, Dahlke MH, Hoogduijn MJ. The life and fate of mesenchymal stem cells. Front Immunol. 2014;5:148.

22. Eggenhofer E, Benseler V, Kroemer A, Popp FC, Geissler EK, Schlitt HJ, Baan CC, Dahlke MH, Hoogduijn MJ. Mesenchymal stem cells are short-lived and do not migrate beyond the lungs after intravenous infusion. Front Immunol. 2012;3(297).

23. Beer L, Mildner M, Ankersmit HJ. Cell secretome based drug substances in regenerative medicine: when regulatory affairs meet basic science. Ann Transl Med. 2017:5(7):170.

24. O'Loughlin AJ, Woffindale CA, Wood MJ. Exosomes and the emerging field of exosome-based gene therapy. Curr Gene Ther. 2012;12(4):262-74.

25. Bermudez MA, Sendon-Lago J, Seoane S, Eiro N, Gonzalez F, Saa J, Vizoso F, Perez-Fernandez R. Anti-inflammatory effect of conditioned medium from human uterine cervical stem cells in uveitis. Exp Eye Res. 2016;149:84-92.

26. Osugi M, Katagiri W, Yoshimi R, Inukai T, Hibi H, Ueda M. Conditioned media from mesenchymal stem cells enhanced bone regeneration in rat calvarial bone defects. Tissue Eng Part A. 2012;18(13-14):1479-89.

27. Yang X, He C, Zhu L, Zhao W, Li S, Xia C, Xu C. Comparative analysis of regulatory role of notch signaling pathway in 8 types liver cell during liver regeneration. Biochem Genet. 2019;57(1):1-19.

28. Hu C, Zhao L, Wu D, Li L. Modulating autophagy in mesenchymal stem cells effectively protects against hypoxia- or ischemia-induced injury. Stem Cell Res Ther. 2019;10(1):120.

29. Zhou WC, Zhang QB, Qiao L. Pathogenesis of liver cirrhosis. World J Gastroenterol. 2014;20(23):7312-24.

30. Mafanda EK, Kandhi R, Bobbala D, Khan MGM, Nandi M, Menendez A, Ramanathan S, llangumaran S. Essential role of suppressor of cytokine signaling 1 (SOCS1) in hepatocytes and macrophages in the regulation of liver fibrosis. Cytokine. 2019;124:154501.

31. Polson J, Lee WM. AASLD position paper: the management of acute liver failure. Hepatology. 2005;41(5):1179-97.

32. Bajaj JS, Moreau R, Kamath PS, Vargas HE, Arroyo V, Reddy KR, Szabo G, Tandon P, Olson J, Karvellas C, Gustot T, Lai JC, Wong F. Acute-on-chronic liver failure: getting ready for prime time? Hepatology. 2018;68(4):1621-32.

33. Riordan SM, Williams R. Mechanisms of hepatocyte injury, multiorgan failure, and prognostic criteria in acute liver failure. Semin Liver Dis. 2003;23(3):203-15.

34. Michalopoulos GK, DeFrances M. Liver regeneration. Adv Biochem Eng Biotechnol. 2005;93:101-34.

35. Jaeschke $\mathrm{H}$ and Lemasters JJ. Apoptosis versus oncotic necrosis in hepatic ischemia/reperfusion injury. (0016-5085 (Print)).

36. Roychowdhury S, McMullen MR, Pisano SG, Liu X, Nagy LE. Absence of receptor interacting protein kinase 3 prevents ethanol-induced liver injury. Hepatology. 2013;57(5):1773-83.

37. Rodriguez-Enriquez S, Kim I, Currin RT, Lemasters JJ. Tracker dyes to probe mitochondrial autophagy (mitophagy) in rat hepatocytes. Autophagy. 2006; 2(1):39-46.

38. Singh R, Kaushik S, Wang Y, Xiang Y, Novak I, Komatsu M, Tanaka K, Cuervo AM, Czaja MJ. Autophagy regulates lipid metabolism. Nature. 2009; 458(7242):1131-5.

39. Malhi H, Gores GJ, Lemasters JJ. Apoptosis and necrosis in the liver: a tale of two deaths? Hepatology. 2006:43(2 Suppl 1):S31-44.

40. Elmore S. Apoptosis: a review of programmed cell death. Toxicol Pathol. 2007;35(4):495-516.

41. Van Cruchten S, Van Den Broeck W. Morphological and biochemical aspects of apoptosis, oncosis and necrosis. Anat Histol Embryol. 2002;31(4):214-23.
42. Hikita H, Takehara T, Kodama T, Shimizu S, Shigekawa M, Hosui A, Miyagi T, Tatsumi T, Ishida H, Li W, Kanto T, Hiramatsu N, Tsujimoto Y, Hayashi N. Delayed-onset caspase-dependent massive hepatocyte apoptosis upon Fas activation in Bak/Bax-deficient mice. Hepatology. 2011;54(1):240-51.

43. Trump BF, Berezesky IK, Chang SH, Phelps PC. The pathways of cell death: oncosis, apoptosis, and necrosis. Toxicol Pathol. 1997;25(1):82-8.

44. Schwabe RF, Luedde T. Apoptosis and necroptosis in the liver: a matter of life and death. Nat Rev Gastroenterol Hepatol. 2018;15(12):738-52.

45. Martin SJ, Henry CM. Distinguishing between apoptosis, necrosis, necroptosis and other cell death modalities. Methods. 2013;61(2):87-9.

46. Sanz-Garcia C, Ferrer-Mayorga G, Gonzalez-Rodriguez A, Valverde AM, Martin-Duce A, Velasco-Martin JP, Regadera J, Fernandez M, Alemany S. Sterile inflammation in acetaminophen-induced liver injury is mediated by Cot/tpl2. J Biol Chem. 2013;288(21):15342-51.

47. Madrigal M, Rao KS, Riordan NH. A review of therapeutic effects of mesenchymal stem cell secretions and induction of secretory modification by different culture methods. J Transl Med. 2014;12:260.

48. Hyenne V, Apaydin A, Rodriguez D, Spiegelhalter C, Hoff-Yoessle S, Diem M, Tak S, Lefebvre O, Schwab Y, Goetz JG, Labouesse M. RAL-1 controls multivesicular body biogenesis and exosome secretion. J Cell Biol. 2015;211(1):27-37.

49. Peterson MF, Otoc N, Sethi JK, Gupta A, Antes TJ. Integrated systems for exosome investigation. Methods. 2015;87:31-45.

50. Lai RC, Yeo RW, Lim SK. Mesenchymal stem cell exosomes. Semin Cell Dev Biol. 2015;40:82-8.

51. Lai RC, Chen TS, Lim SK. Mesenchymal stem cell exosome: a novel stem cell-based therapy for cardiovascular disease. Regen Med. 2011;6(4):481-92.

52. Tian T, Zhu YL, Zhou YY, Liang GF, Wang YY, Hu FH, Xiao ZD. Exosome uptake through clathrin-mediated endocytosis and macropinocytosis and mediating miR-21 delivery. J Biol Chem. 2014;289(32):22258-67.

53. Mulcahy LA, Pink RC, Carter DR. Routes and mechanisms of extracellular vesicle uptake. J Extracell Vesicles. 2014;3.

54. Parolini I, Federici C, Raggi C, Lugini L, Palleschi S, De Milito A, Coscia C, lessi E, Logozzi M, Molinari A, Colone M, Tatti M, Sargiacomo M, Fais S. Microenvironmental $\mathrm{pH}$ is a key factor for exosome traffic in tumor cells. J Biol Chem. 2009;284(49):34211-22.

55. Kim HS, Choi DY, Yun SJ, Choi SM, Kang JW, Jung JW, Hwang D, Kim KP, Kim DW. Proteomic analysis of microvesicles derived from human mesenchymal stem cells. J Proteome Res. 2012;11(2):839-49.

56. Angulski AB, Capriglione LG, Batista M, Marcon BH, Senegaglia AC, Stimamiglio MA, Correa A. The protein content of extracellular vesicles derived from expanded human umbilical cord blood-derived CD133(+) and human bone marrow-derived mesenchymal stem cells partially explains why both sources are advantageous for regenerative medicine. Stem Cell Rev Rep. 2017;13(2):244-57.

57. Anderson JD, Johansson HJ, Graham CS, Vesterlund M, Pham MT, Bramlett CS, Montgomery EN, et al. Comprehensive proteomic analysis of mesenchymal stem cell exosomes reveals modulation of angiogenesis via nuclear factor-kappaB signaling. Stem Cells. 2016;34(3):601-13.

58. La Greca A, Solari C, Furmento V, Lombardi A, Biani MC, Aban C, Moro L, García M, Guberman AS, Sevlever GE, Miriuka SG, Luzzani C. Extracellular vesicles from pluripotent stem cell-derived mesenchymal stem cells acquire a stromal modulatory proteomic pattern during differentiation. Exp Mol Med. 2018;50(9):119.

59. Lai RC, Tan SS, Teh BJ, Sze SK, Arslan F, de Kleijn DP, Choo A, Lim SK. Proteolytic potential of the MSC exosome proteome: implications for an exosome-mediated delivery of therapeutic proteasome. Int J Proteomics. 2012;2012:971907.

60. Eirin A, Zhu XY, Puranik AS, Woollard JR, Tang H, Dasari S, Lerman A, van Wijnen AJ, Lerman LO. Comparative proteomic analysis of extracellular vesicles isolated from porcine adipose tissue-derived mesenchymal stem/ stromal cells. Sci Rep. 2016;6:36120.

61. Salomon C, Ryan J, Sobrevia L, Kobayashi M, Ashman K, Mitchell M, Rice GE. Exosomal signaling during hypoxia mediates microvascular endothelial cell migration and vasculogenesis. PLoS One. 2013;8(7):e68451.

62. Kilpinen L, Impola U, Sankkila L, Ritamo I, Aatonen M, Kilpinen S, Tuimala J, Valmu L, Levijoki J, Finckenberg P, Siljander P, Kankuri E, Mervaala E, Laitinen S. Extracellular membrane vesicles from umbilical cord blood-derived MSC protect against ischemic acute kidney injury, a feature that is lost after inflammatory conditioning. J Extracell Vesicles. 2013;2.

63. Zhu LP, Tian T, Wang JY, He JN, Chen T, Pan M, Xu L, Zhang HX, Qiu XT, Li CC, Wang KK, Shen H, Zhang GG, Bai YP. Hypoxia-elicited mesenchymal 
stem cell-derived exosomes facilitates cardiac repair through miR-125bmediated prevention of cell death in myocardial infarction. Theranostics. 2018;8(22):6163-77.

64. Zhang B, Shen L, Shi H, Pan Z, Wu L, Yan Y, Zhang X, Mao F, Qian H, Xu W. Exosomes from human umbilical cord mesenchymal stem cells: identification, purification, and biological characteristics. Stem Cells Int. 2016; 2016:1929536

65. Yang XX, Sun C, Wang L, Guo XL. New insight into isolation, identification techniques and medical applications of exosomes. J Control Release. 2019; 308:119-29.

66. van der Pol E, Coumans FA, Grootemaat AE, Gardiner C, Sargent IL, Harrison P, Sturk A, van Leeuwen TG, Nieuwland R. Particle size distribution of exosomes and microvesicles determined by transmission electron microscopy, flow cytometry, nanoparticle tracking analysis, and resistive pulse sensing. J Thromb Haemost. 2014;12(7):1182-92.

67. Danielson KM, Estanislau J, Tigges J, Toxavidis V, Camacho V, Felton EJ, Khoory J, Kreimer S, Ivanov AR, Mantel PY, Jones J, Akuthota P, Das S, Ghiran I. Diurnal variations of circulating extracellular vesicles measured by nano flow cytometry. PLoS One. 2016;11(1):e0144678.

68. Nizamudeen Z, Markus R, Lodge R, Parmenter C, Platt M, Chakrabarti L, Sottile $V$. Rapid and accurate analysis of stem cell-derived extracellular vesicles with super resolution microscopy and live imaging. Biochim Biophys Acta Mol Cell Res. 2018;1865(12):1891-900.

69. Kabe Y, Suematsu M, Sakamoto S, Hirai M, Koike I, Hishiki T, Matsuda A, Hasegawa Y, Tsujita K, Ono M, Minegishi N, Hozawa A, Murakami Y, Kubo M, Itonaga $\mathrm{M}, \mathrm{Handa} \mathrm{H}$. Development of a highly sensitive device for counting the number of disease-specific exosomes in human sera. Clin Chem. 2018; 64(10):1463-73.

70. Görgens A, Bremer M, Ferrer-Tur R, Murke F, Tertel T, Horn PA, Thalmann S, Welsh JA, Probst C, Guerin C, Boulanger CM, Jones JC, Hanenberg H, Erdbrügger U, Lannigan J, Ricklefs FL, El-Andaloussi S, Giebel B. Optimisation of imaging flow cytometry for the analysis of single extracellular vesicles by using fluorescence-tagged vesicles as biological reference material. J Extracell Vesicles. 2019;8(1):1587567.

71. Chen YS, Lin EY, Chiou TW, Harn HJ. Exosomes in clinical trial and their production in compliance with good manufacturing practice. Ci Ji Yi Xue Za Zhi. 2019;32(2):113-20.

72. Théry C, Witwer KW, Aikawa E, Alcaraz MJ, Anderson JD, Andriantsitohaina $R$, Antoniou $A$, et al. Minimal information for studies of extracellular vesicles 2018 (MISEV2018): a position statement of the International Society for Extracellular Vesicles and update of the MISEV2014 guidelines. J Extracell Vesicles. 2018;7(1):1535750.

73. Stuffers S, Sem Wegner C, Stenmark H, Brech A. Multivesicular endosome biogenesis in the absence of ESCRTs. Traffic. 2009;10(7):925-37.

74. Kowal J, Arras G, Colombo M, Jouve M, Morath JP, Primdal-Bengtson B, Dingli F, Loew D, Tkach M, Théry C. Proteomic comparison defines novel markers to characterize heterogeneous populations of extracellular vesicle subtypes. Proc Natl Acad Sci U S A. 2016;113(8):E968-77.

75. Lee Y, El Andaloussi S, Wood MJ. Exosomes and microvesicles: extracellular vesicles for genetic information transfer and gene therapy. Hum Mol Genet. 2012;21(R1):R125-34

76. Fitzmaurice C, Abate D, Abbasi N, Abbastabar H, Abd-Allah F, AbdelRahman O, Abdelalim A, et al. Global, regional, and national cancer incidence, mortality, years of life lost, years lived with disability, and disability-adjusted life-years for 29 cancer groups, 1990 to 2017: a systematic analysis for the global burden of disease study. JAMA Oncol. 2019;5(12): 1749-68.

77. Willis GR, Kourembanas S, Mitsialis SA. Toward exosome-based therapeutics: isolation, heterogeneity, and fit-for-purpose potency. Front Cardiovasc Med. 2017:4:63.

78. Pacienza N, Lee RH, Bae EH, Kim DK, Liu Q, Prockop DJ, Yannarelli G. In vitro macrophage assay predicts the in vivo anti-inflammatory potential of exosomes from human mesenchymal stromal cells. Mol Ther Methods Clin Dev. 2019;13:67-76.

79. Chen YX, Zeng ZC, Sun J, Zeng HY, Huang Y, Zhang ZY. Mesenchymal stem cell-conditioned medium prevents radiation-induced liver injury by inhibiting inflammation and protecting sinusoidal endothelial cells. J Radiat Res. 2015;56(4):700-8.

80. Du Z, Wei C, Cheng K, Han B, Yan J, Zhang M, Peng C, Liu Y. Mesenchymal stem cell-conditioned medium reduces liver injury and enhances regeneration in reduced-size rat liver transplantation. J Surg Res. 2013; 183(2):907-15.

81. Huang B, Cheng X, Wang H, Huang W, la Ga HZ, Wang D, Zhang K, Zhang H, Xue Z, Da Y, Zhang N, Hu Y, Yao Z, Qiao L, Gao F, Zhang R. Mesenchymal stem cells and their secreted molecules predominantly ameliorate fulminant hepatic failure and chronic liver fibrosis in mice respectively. J Transl Med. 2016;14:45.

82. Kim YH, Cho KA, Park M, Kim HS, Park JW, Woo SY, Ryu KH. Conditioned medium from tonsil-derived mesenchymal stem cells relieves CCl4-induced liver fibrosis in mice. Tissue Eng Regen Med. 2019;16(1):51-8.

83. Tamura R, Uemoto S, Tabata Y. Immunosuppressive effect of mesenchymal stem cell-derived exosomes on a concanavalin A-induced liver injury model. Inflamm Regen. 2016;36:26.

84. Du Y, Li D, Han C, Wu H, Xu L, Zhang M, Zhang J, Chen X. Exosomes from human-induced pluripotent stem cell-derived mesenchymal stromal cells (hiPSC-MSCs) protect liver against hepatic ischemia/ reperfusion injury via activating sphingosine kinase and sphingosine-1-phosphate signaling pathway. Cell Physiol Biochem. 2017;43(2):611-25.

85. Jiang L, Zhang S, Hu H, Yang J, Wang X, Ma Y, Jiang J, Wang J, Zhong L, Chen M, Wang H, Hou Y, Zhu R, Zhang Q. Exosomes derived from human umbilical cord mesenchymal stem cells alleviate acute liver failure by reducing the activity of the NLRP3 inflammasome in macrophages. Biochem Biophys Res Commun. 2019;508(3):735-41.

86. Chen $L$, Xiang B, Wang $X$, Xiang C. Exosomes derived from human menstrual blood-derived stem cells alleviate fulminant hepatic failure. Stem Cell Res Ther. 2017;8(1):9.

87. Jiang W, Tan Y, Cai M, Zhao T, Mao F, Zhang X, Xu W, Yan Z, Qian H, Yan Y. Human umbilical cord MSC-derived exosomes suppress the development of CCl4-induced liver injury through antioxidant effect. Stem Cells Int. 2018; 2018:6079642

88. Rong X, Liu J, Yao X, Jiang T, Wang Y, Xie F. Human bone marrow mesenchymal stem cells-derived exosomes alleviate liver fibrosis through the Wnt/beta-catenin pathway. Stem Cell Res Ther. 2019;10(1):98.

89. Li T, Yan Y, Wang B, Qian H, Zhang X, Shen L, Wang M, Zhou Y, Zhu W, Li $\mathrm{W}, \mathrm{Xu} \mathrm{W}$. Exosomes derived from human umbilical cord mesenchymal stem cells alleviate liver fibrosis. Stem Cells Dev. 2013;22(6):845-54.

90. Liu Y, Lou G, Li A, Zhang T, Qi J, Ye D, Zheng M, Chen Z. AMSC-derived exosomes alleviate lipopolysaccharide/d-galactosamine-induced acute liver failure by miR-17-mediated reduction of TXNIP/NLRP3 inflammasome activation in macrophages. EBioMed. 2018;36:140-50.

91. Yan Y, Jiang W, Tan Y, Zou S, Zhang H, Mao F, Gong A, Qian H, Xu W. hucMSC exosome-derived GPX1 is required for the recovery of hepatic oxidant injury. Mol Ther. 2017;25(2):465-79.

92. Das R, Jahr H, van Osch GJ, Farrell E. The role of hypoxia in bone marrowderived mesenchymal stem cells: considerations for regenerative medicine approaches. Tissue Eng Part B Rev. 2010;16(2):159-68.

93. Hawkins KE, Sharp TV, McKay TR. The role of hypoxia in stem cell potency and differentiation. Regen Med. 2013;8(6):771-82.

94. Kiani AA, Kazemi A, Halabian R, Mohammadipour M, Jahanian-Najafabadi A, Roudkenar MH. HIF-1alpha confers resistance to induced stress in bone marrow-derived mesenchymal stem cells. Arch Med Res. 2013;44(3):185-93.

95. Temnov A, Rogov K, Zhalimov V, Igor P, Pekov S, Bader A, Sklifas A, Giri S. The effect of a mesenchymal stem cell conditioned medium fraction on morphological characteristics of hepatocytes in acetaminophen-induced acute liver failure: a preliminary study. Hepat Med. 2019;11:89-96.

96. Lee SC, Jeong HJ, Lee SK, Kim SJ. Hypoxic conditioned medium from human adipose-derived stem cells promotes mouse liver regeneration through JAK/STAT3 signaling. Stem Cells Transl Med. 2016;5(6):816-25.

97. Temnov AA, Rogov KA, Sklifas AN, Klychnikova EV, Hartl M, Djinovic-Carugo K, Charnagalov A. Protective properties of the cultured stem cell proteome studied in an animal model of acetaminophen-induced acute liver failure. Mol Biol Rep. 2019:46(3):3101-12.

98. Chen L, Zhang J, Yang L, Zhang G, Wang Y, Zhang S. The effects of conditioned medium derived from mesenchymal stem cells cocultured with hepatocytes on damaged hepatocytes and acute liver failure in rats. Stem Cells Int. 2018;2018:9156560.

99. Sun $\mathrm{CK}$, Chen $\mathrm{CH}$, Chang $\mathrm{CL}$, Chiang HJ, Sung PH, Chen $\mathrm{KH}$, Chen $\mathrm{YL}$, Chen SY, Kao GS, Chang HW, Lee MS, Yip HK. Melatonin treatment enhances therapeutic effects of exosomes against acute liver ischemia-reperfusion injury. Am J Transl Res. 2017;9(4):1543-60. 
100. Valadi H, Ekstrom K, Bossios A, Sjostrand M, Lee JJ, Lotvall JO. Exosomemediated transfer of mRNAs and microRNAs is a novel mechanism of genetic exchange between cells. Nat Cell Biol. 2007;9(6):654-9.

101. Chen L, Lu FB, Chen DZ, Wu JL, Hu ED, Xu LM, Zheng MH, Li H, Huang Y, Jin XY, Gong YW, Lin Z, Wang XD, Chen YP. BMSCs-derived miR-223containing exosomes contribute to liver protection in experimental autoimmune hepatitis. Mol Immunol. 2018;93:38-46.

102. Qu Y, Zhang Q, Cai X, Li F, Ma Z, Xu M, Lu L. Exosomes derived from miR181-5p-modified adipose-derived mesenchymal stem cells prevent liver fibrosis via autophagy activation. J Cell Mol Med. 2017;21(10):2491-502.

103. Rani S, Ryan AE, Griffin MD, Ritter T. Mesenchymal stem cell-derived extracellular vesicles: toward cell-free therapeutic applications. Mol Ther. 2015;23(5):812-23

\section{Publisher's Note}

Springer Nature remains neutral with regard to jurisdictional claims in published maps and institutional affiliations. 